\title{
PPM LATIHAN KERJA BAGI MASYARAKAT TENTANG DISAIN DAN KONSTRUKSI BAJA RINGAN DI KOTA MANADO
}

\author{
Heindrcih Taunaumang; Arong F. Sompotan \\ Jurusan Fisika, Fakultas Matematika dan Ilmu Pengetahuan Alam, \\ Universitas Negeri Manado \\ ftaslam@unima.ac.id
}

\begin{abstract}
Abstrak
Perkembangan penggunaan material/bahan bangunan rumah dengan menggunakan material logam seperti atap seng berbasis baja ringan, gantungan baju, lemari, rak cepatu dll semakin pesat karena dengan menggunakan material tersebut lebih tahan lama dan relatif lebih cepat pekerjaan diselesaikan. Namun demikian pengerjaan konstruksi bangunan/rumah/garasi dengan atap seng atau gantungan baju, lemari, rak cepatu dll berbasis baja ringan diperlukan pengetahuan tentang material, disain dan konstruksi serta ketrampilan dalam pembuatannya. Masyarakat di Kelurahan Titiwungen Selatan, Kecamatan Sario Kota Manado kalah bersaing dalam mengerjakan konstruksi bangunan/rumah dengan atap seng berbasis baja ringan karena mereka hanya terbiasa dengan mengerjakan atap seng berbasis kayu (konstruksi dengan bahan kayu). Disamping kekurangan tentang pengetahuan disain dan konstruksi atap seng, gantungan baju, lemari dan rak cepatu dengan baja ringan mereka juga belum memiliki ketrampilan serta peralatan seperti bor-elektrik. Dengan demikian mereka kurang berdaya dan kehilangan peluang kerja sehingga sangat berdampak pada masalah ekonomi/pendapatan keluarga. Oleh karena itu melalui pengabdian kepada masyarakat yang dibiayai oleh LPPM Unima ini kami ingin melaksanakan kegiatan pengabdian dengan judul : "PPM LATIHAN KERJA BAGI MASYARAKAT TENTANG DISAIN DAN KONSTRUKSI BAJA RINGAN DI KOTA MANADO

Tulisan ini kiranya boleh memberikan kontribusi nyata memecahkan persoalan dalam mengatasi persoalan ketrampilan tenaga kerja di Kota Manado khususnya di Kelurahan Titiwungen Selatan, Kecamatan Sario. Kami percaya melalui kegiatan latihan kerja bagi masyarakat akan berhasil dan bemanfaat karena kerjasama Perguruan Tinggi (Unima), masyarakat Kelurahan Titiwungen Seatan, Kecamatan Sario dan pemerintah Kota Manado..
\end{abstract}

Kata kunci: Mayarakat, Tukang, Baja-Ringan, Disain

\section{PENDAHULUAN}

\section{Perkembangan penggunaan}

material/bahan bangunan rumah, gantungan baju, lemari dan rak cepatu dll dengan menggunakan atap seng berbasis baja ringan semakin pesat karena dengan menggunakan material tersebut lebih tahan lama dan relatif

lebih cepat pekerjaan diselesaikan. Namun demikian pengerjaan konstruksi seperti bangunan/rumah/garasi, lemari baju, gantungan baju dan rak cepatu dengan atap seng berbasis baja ringan diperlukan pengetahuan tentang 
material, disain dan konstruksi serta ketrampilan dalam pembuatannya. Berdasarkan pengamatan kami bahwa, Masyarakat-Tukang di Kelurahan Titiwungen Selatan, Kecamatan Sario Kota Manado kalah bersaing dengan tenaga kerja dari luar daerah dalam mengerjakan konstruksi bangunan/rumah dengan atap seng, membuat gantungan baju, lemari dan rak cepatu berbasis baja ringan karena mereka hanya terbiasa dengan mengerjakan atap seng berbasis bahan kayu (konstruksi dengan bahan kayu). Disamping kekurangan tentang pengetahuan disain dan kosntruksi atap seng, membuat gantungan baju, lemari dan rak cepatu dengan baja ringan mereka juga belum memiliki ketrampilan serta peralatan seperti bor-elektrik. Dengan demikian mereka kehilangan peluang kerja sehingga sangat berdampak pada masalah ekonomi/pendapatan keluarga.

Kami percaya bahwa melalui Pendidikan dan Latihan Kerjja sebagai solusi tepat untuk memberikan pengetahuan dan ketrampilan bagi masyarakat-tukang agar mereka boleh bersaing dan mendapat peluang kerja dan akhirnya dapat meningkatkan pendapatan keluarga.

Konstruksi bangunan rumah/garasi dengan atap seng, membuat gantungan baju, lemari dan rak cepatu berbasis baja ringan ditunjukkan pada gambar 1.1-1.6.

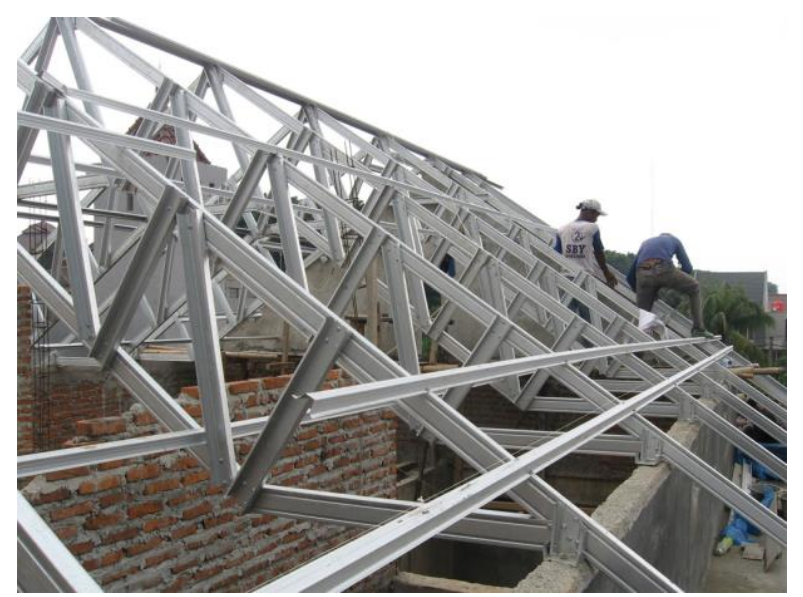

Gambar 1.1. Konstruksi Atap Seng Berbasis Baja Ringan

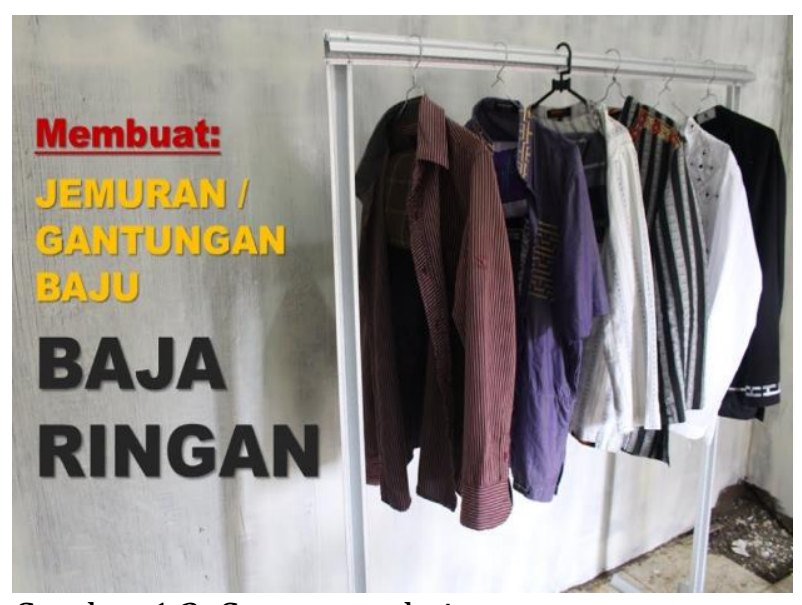

Gambar 1.2. Gantungan baju 


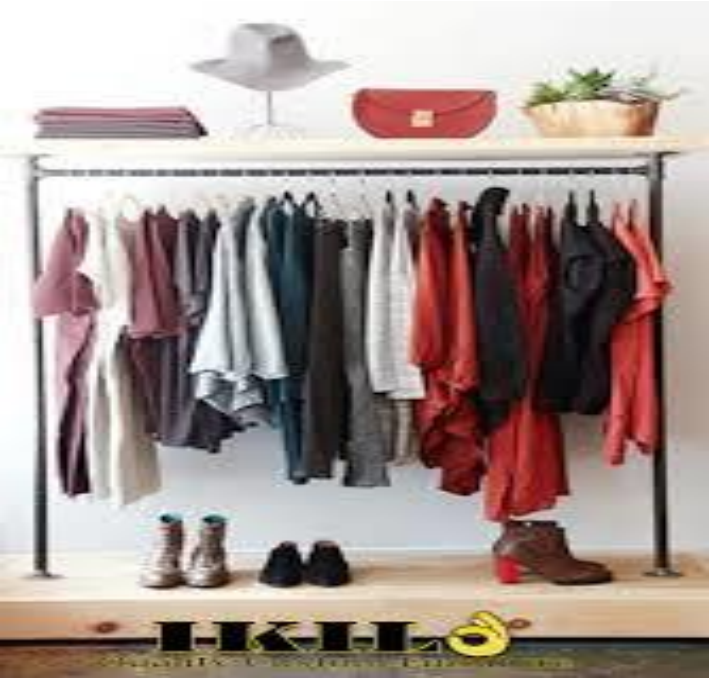

Gambar 1.2. Gantungan baju

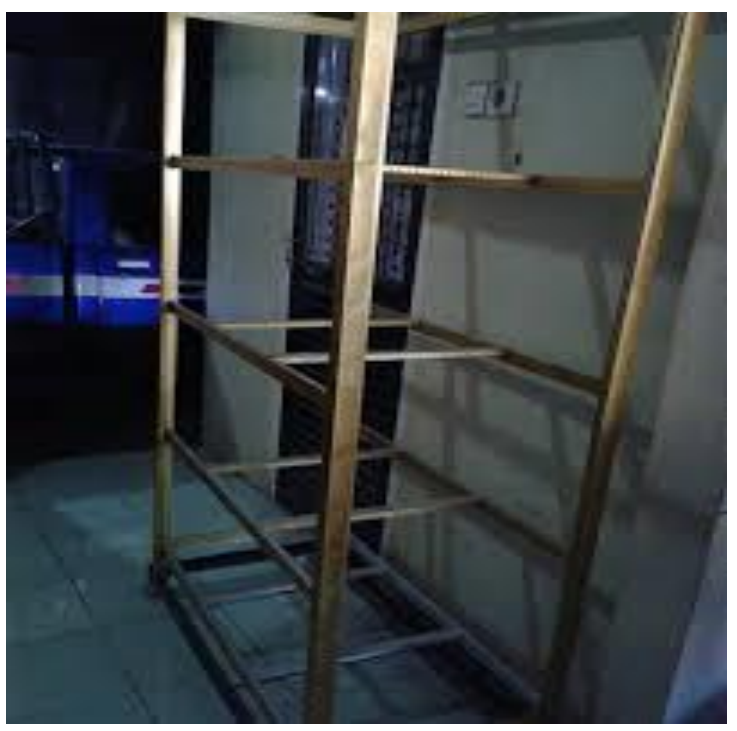

Gambar 1.4. Konstruksi Lemari

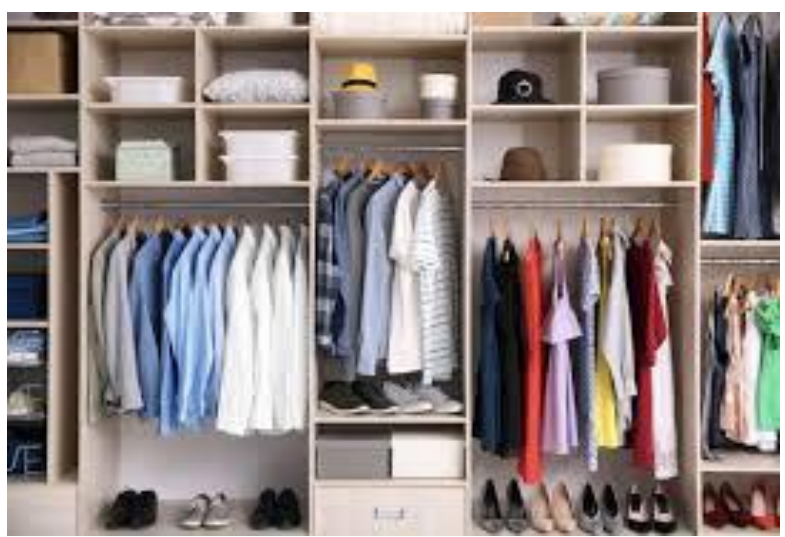

Gambar 1.5. Lemari baju

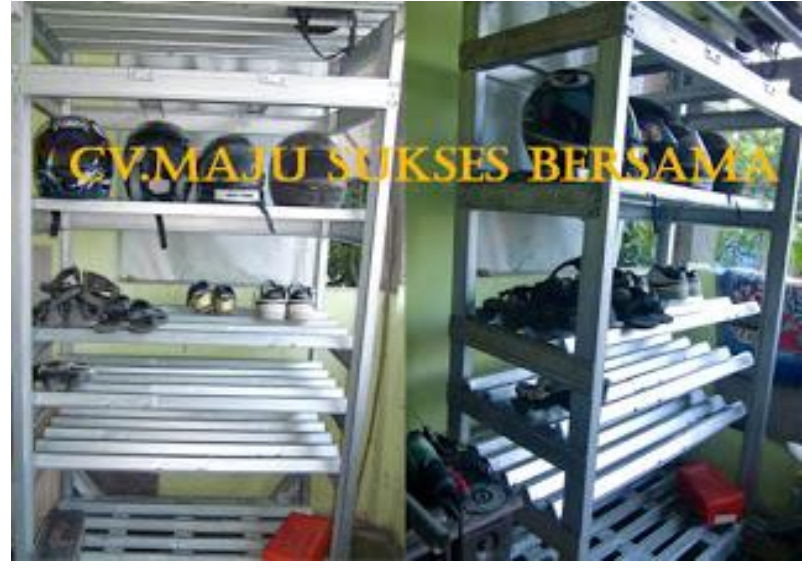

Gambar 1.6. Rak cepatu

Dalam rangka untuk membantu peningkatan pengetahuan dan ketrampilan masyarakat-tukang tentang disain dan konstruksi bangunan dengan atap seng membuat gantungan baju, lemari dan rak cepatu berbasis baja ringan maka sangat diperlukan intervensi Perguruan Tinggi Universitas Negeri Manado dengan program pengabdian masyarakat disamping dalam rangka aplikasi ilmu pengetahuan tetapi juga untuk memberdayakan masyarakattukang sehingga mereka boleh memperoleh pendapatan yang cukup untuk penghidupan keluarga. Pengusul proposal ini sebagai dosen Unima terpanggil dalam memberikan kontribusi nyata memecahkan masalah berkaitan dengan pengetahuan dan ketrampilan tenga kerja lokal.

Laporan kegiatan pengabdian kepada masyarakat ini adalah dengan judul : "PPM LATIHAN KERJA BAGI MASYARAKAT TENTANG DISAIN DAN KONSTRUKSI BAJA RINGAN DI KOTA MANADO “

Kegiatan pengabdian ini kiranya memberikan kontribusi nyata memecahkan persoalan dalam mengatasi persoalan ketrampilan tenaga kerja di Kota manado khususnya di Kelurahan Titiwungen Selatan, Kecamatan Sario. Kami percaya melalui kegiatan latihan kerja bagi masyarakat-tukang akan berhasil dan bemanfaat karena kerjasama Perguruan Tinggi (Unima), masyarakat 
kelurahan Titiwungen Seatan, Kecamatan Sario dan pemerintah Kota Manado.

\section{METODE PELAKSANAAN}

Metode pelaksanaan kegiatan pengabdian ini adalah sebagai berikut:

\subsection{Tahap Persiapan}

waktu

Penentuan lokasi dan pertemuan/koordinasi

Pemerintah Kelurahan Sario Titiwungen Selatan dan Masyarakat/Tukang di Kelurahan Sario Titiwungen Selatan.

\subsection{Tahap Pelaksanaan}

\section{- $\quad$ Persiapan bahan, alat}

- Penjelasan/pelatihan

pembuatan disain/perancangan dan konstruksi bangunan dengan atap seng, membuat gantungan baju, lemari dan rak cepatu berbasis baja ringan.

- $\quad$ Pelaksanaan latihan kerja tentang disain/perancangan dan pembuatan konstruksi bangunan atap seng, membuat gantungan baju, lemari dan rak cepatu berbasis baja ringan.

\subsection{Tahap evaluasi /perbaikan}

\subsection{Tahap pelaporan}

Metode pelaksanaan pengabdian kepada masyarakat ini meliputi tahapan sebagaimana ditunjukkan pada gambar 2.1 .

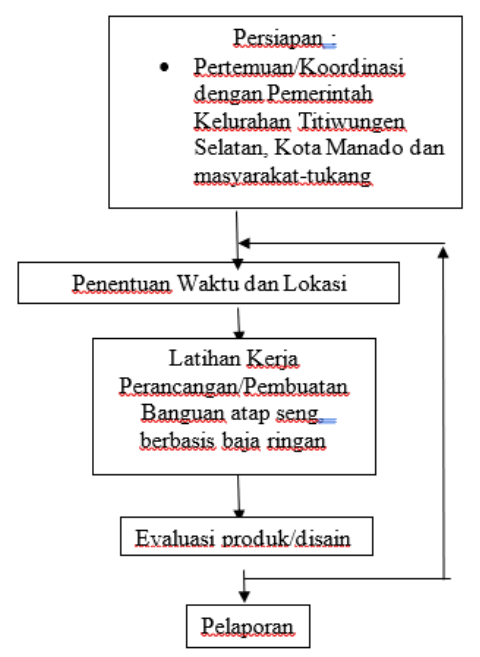

Gambar 2.1. Skema tahapan kegiatan pengabdian PPM

\section{HASIL DAN PEMBAHASAN}

\subsection{Hasil}

Kegiatan ini telah dilaksanakan pada hari Jumat, tanggal 18-19 Juli 202019. Tempat lokasi Kelurahan Titiwungen Selatan Lingkungan 2 Kecamatan Sario KotaManado. Judul kegiatan ini sebagaiman ditunjukkan pada Gambar 3.1.

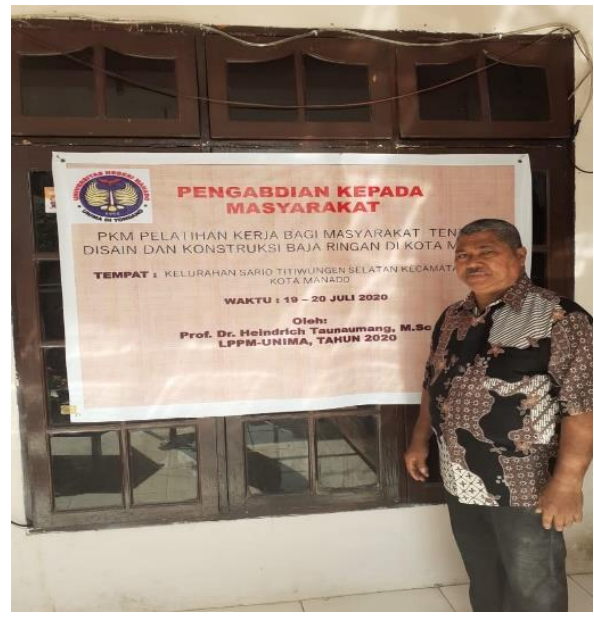

Gambar 3.1. Kegiatan PKM LPPM Tahun 2020 oleh Prof. Dr. Heindrich

Taunaumang, M.Sc.

Bahan baja ringan yang telah disiapkan sebagaimana ditunjukkan pada Gambar 4.2-4.3.

a. Symphoni Truus c.75

b. CBM Hollow $16 \times 32$

A. T 045, SNI 4096: 2007. ISO 9001: 2015

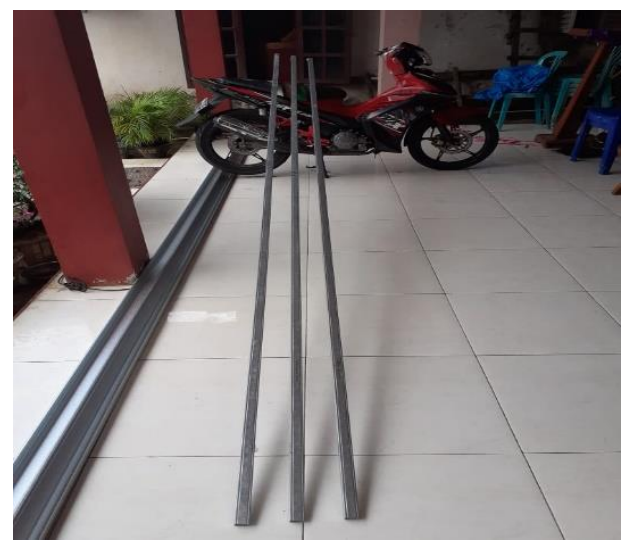

Gambar 3.2. Bahan baja ringan dengan tipe CBM Hollow 16x32 yang telah disiapkan untuk kegiatan PPM 
Jurnal ABDIMAS, Vol. 13, No. 1, April 2020

ISSN: 1979-0953 | e-ISSN: 2598-6066

Peralatan yang telah disiapkan adalah sebagaimana ditunjukkan pada Gambar 4.4a$4.4 \mathrm{e}$.

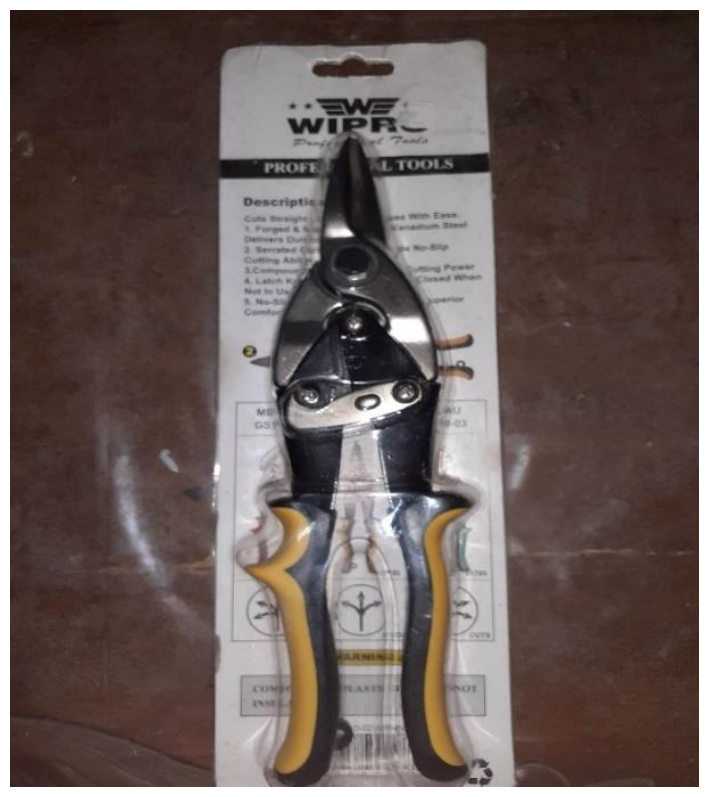

Gambar 3.4.a. Cutter

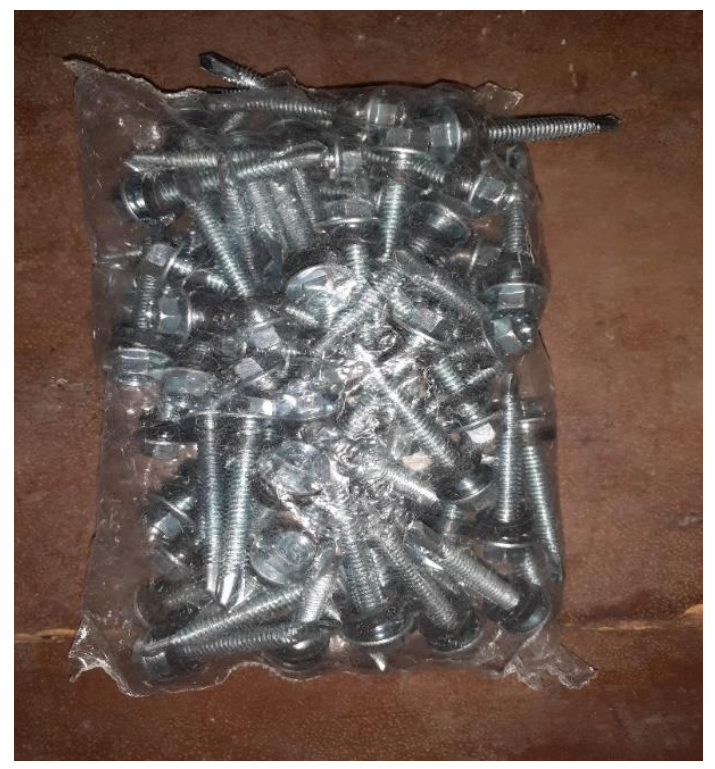

Gambar 3.4b. Paku seng

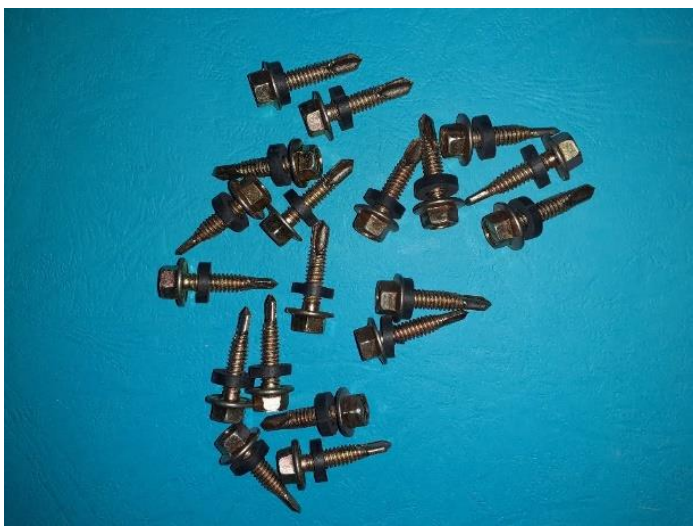

Gambar3.4c. Paku untuk tiang dan sambungan.

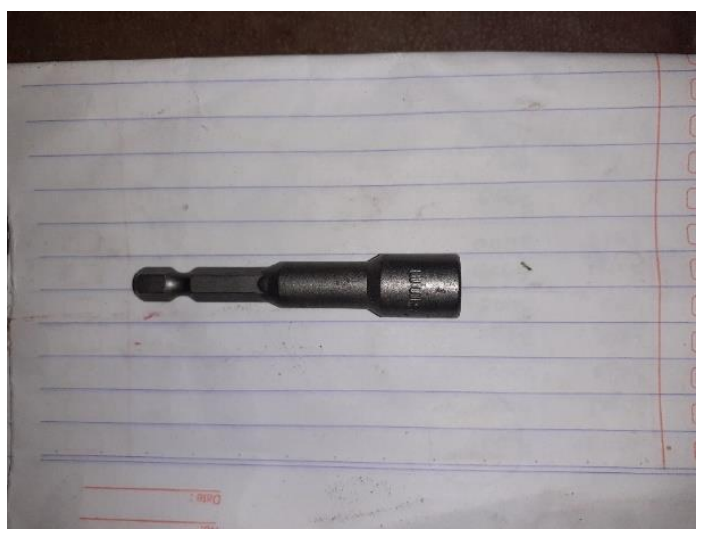

Gambar 3.4d. Komponen pemutar bor

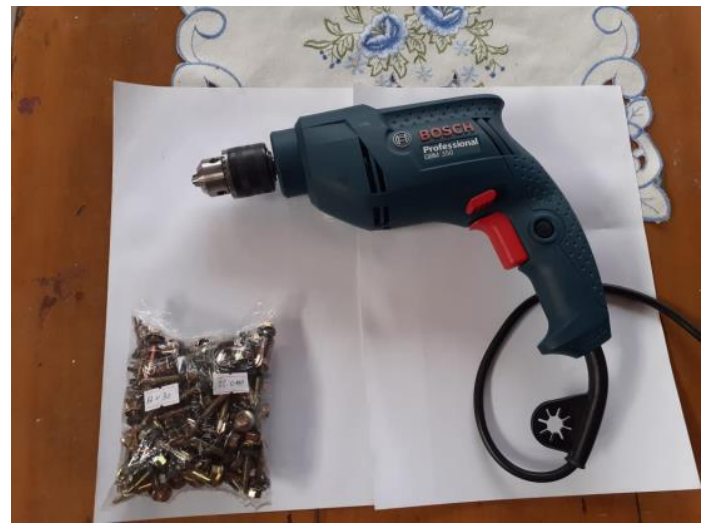

Gambar 3.5d. Bor listrik 
Jurnal ABDIMAS, Vol. 13, No. 1, April 2020

ISSN: 1979-0953 | e-ISSN: 2598-6066

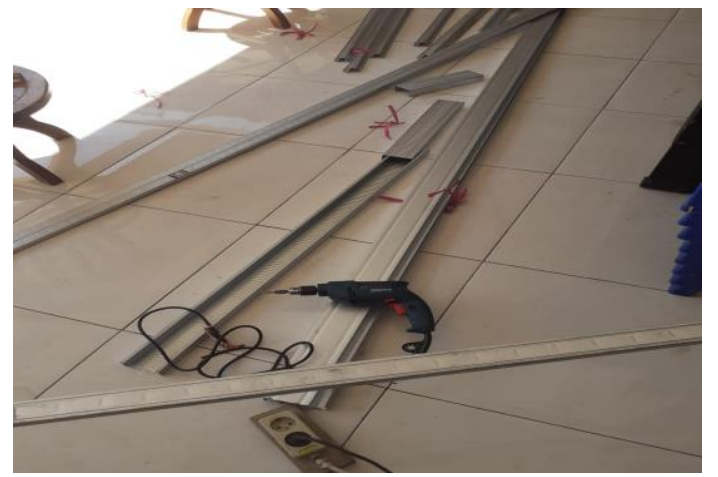

Gambar 3.6. Proses pemotongan baja ringan untuk gantungan handuk

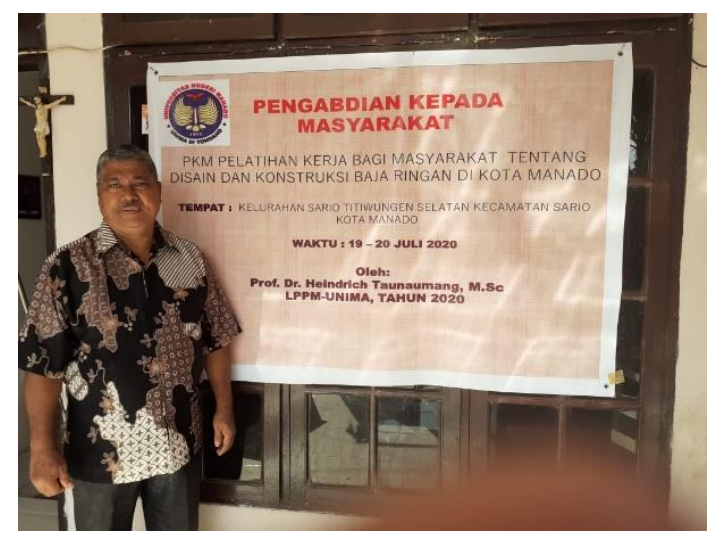

Gambar 3.7. Pengabdi memberikan penjelasan maksud kegiatan PPM

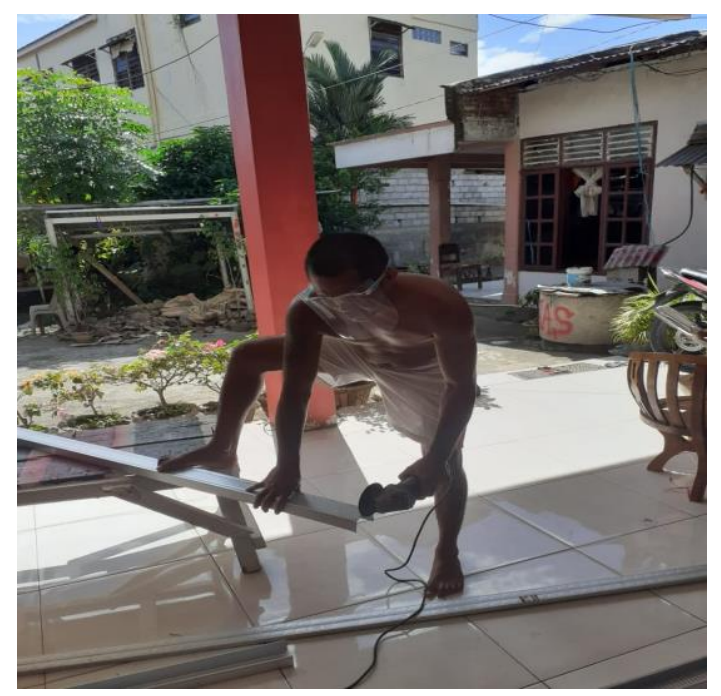

Gambar 3.8. Peserta pelatihan melakukan pemotongan taso (baja ringan) dengan menggunakan pemotong elektrik.Untuk tiang dengan panjang 1,48 meter, dan $120 \mathrm{~cm}$.

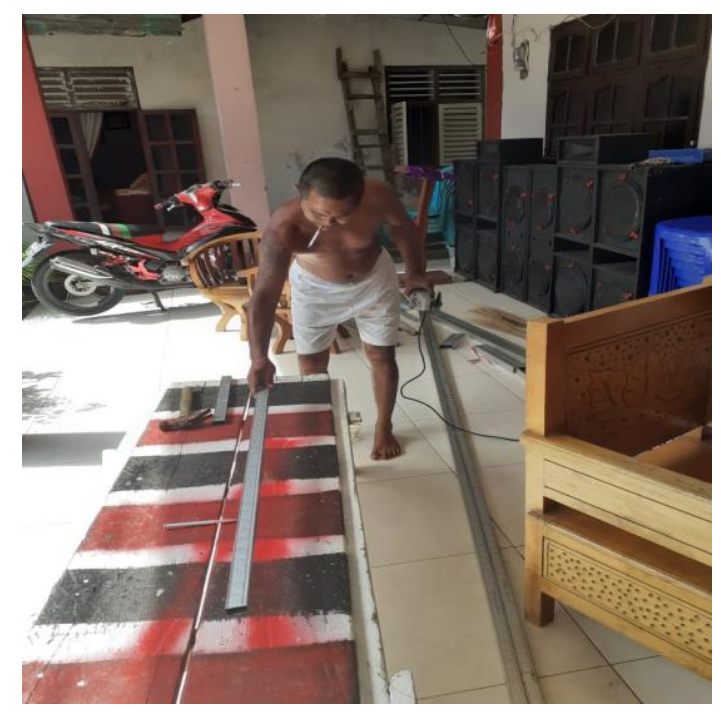

Gambar 3.9. Peserta pelatihan melakukan pemotongan taso (baja ringan) dengan menggunakan pemotong elektrik.Untuk tiang dengan panjang 1,48 meter, dan $120 \mathrm{~cm}$.

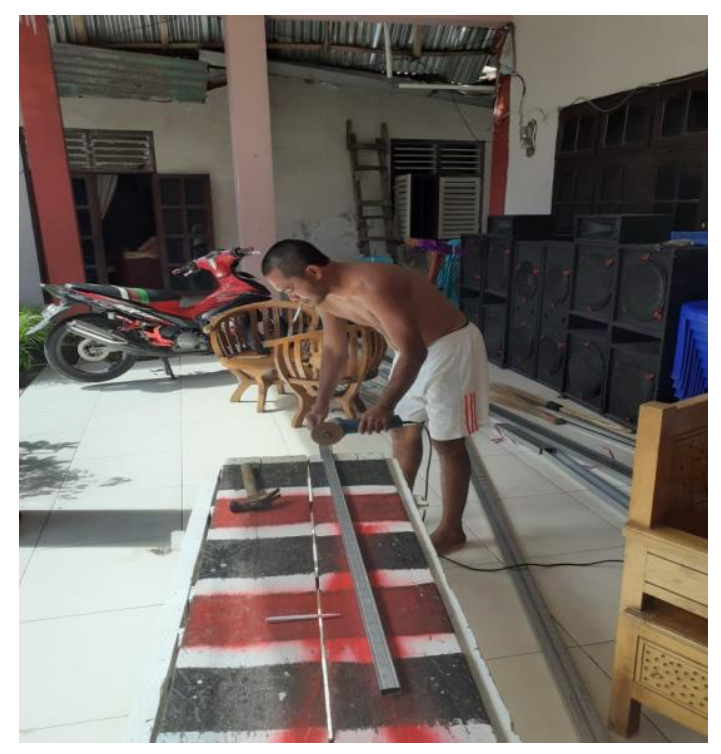

Gambar 3.10. Peserta pelatihan melakukan pemotongan taso (baja ringan) dengan menggunakan pemotong elektrik.Untuk tiang dengan panjang 1,48 meter, dan $120 \mathrm{~cm}$. 
Jurnal ABDIMAS, Vol. 13, No. 1, April 2020 ISSN: 1979-0953 | e-ISSN: 2598-6066

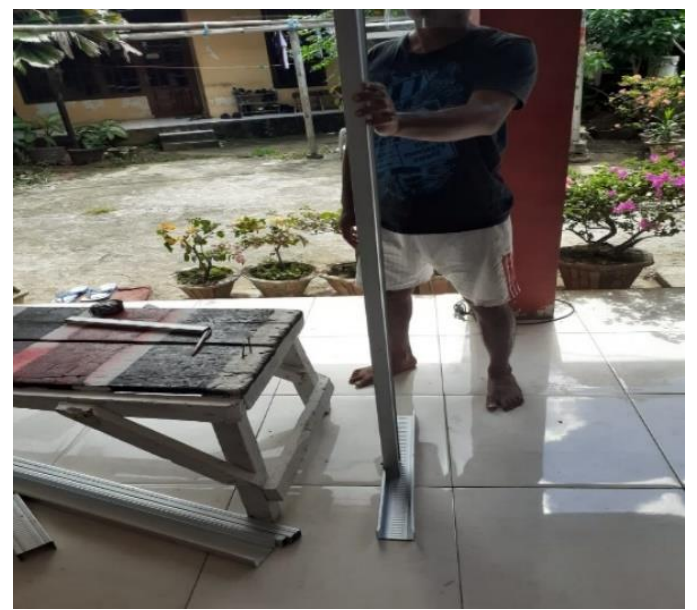

Gambar 3.11. Peserta pelatihan melakukan prakitan satu tiang dengan panjang 1,48 meter, dan $120 \mathrm{~cm}$

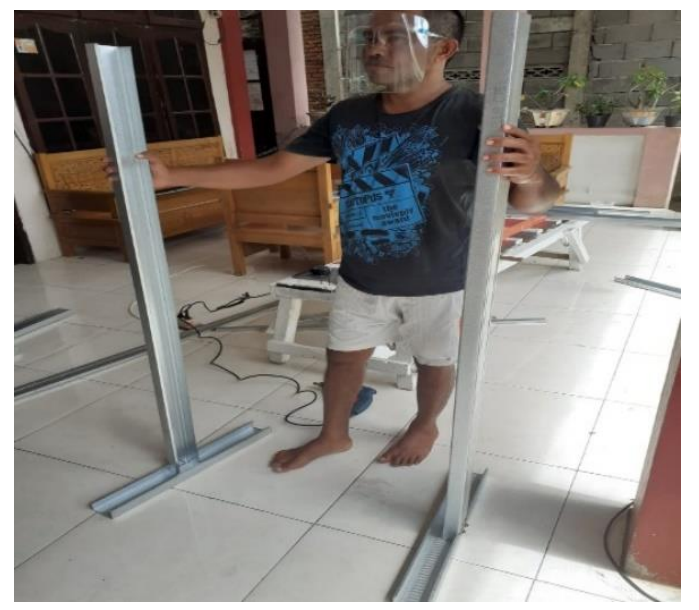

Gambar 3.12. Peserta pelatihan melakukan prakitan dua tiang dengan panjang 1,48 meter, dan $120 \mathrm{~cm}$.

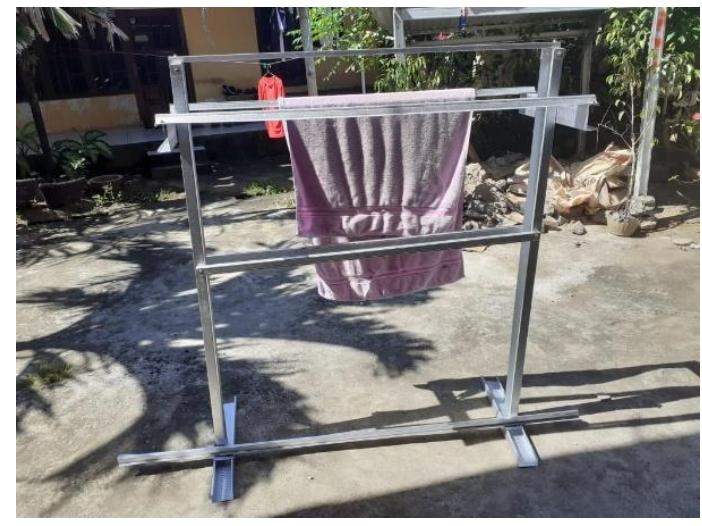

Gambar 3.13. Uji coba Gantungn handuk masih goyah

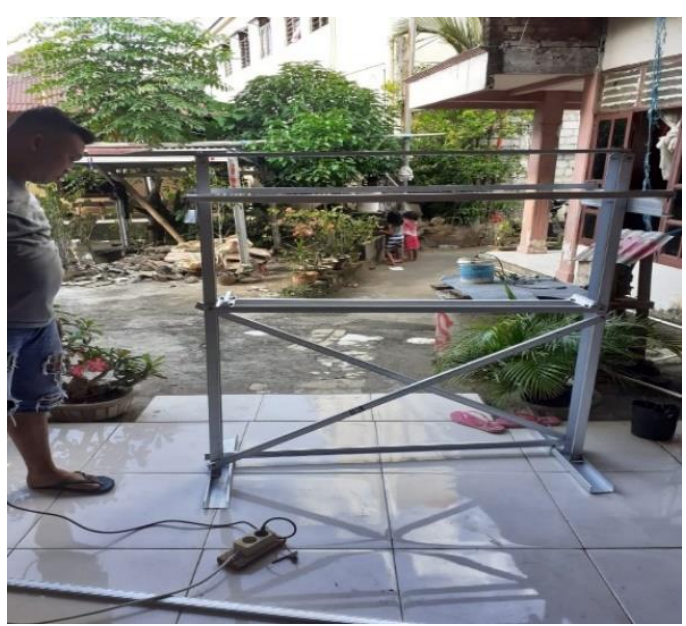

Gambar 3.14 Instruktur selesai memasang skor gantungan handuk untuk penguatan (tidak goyah) .

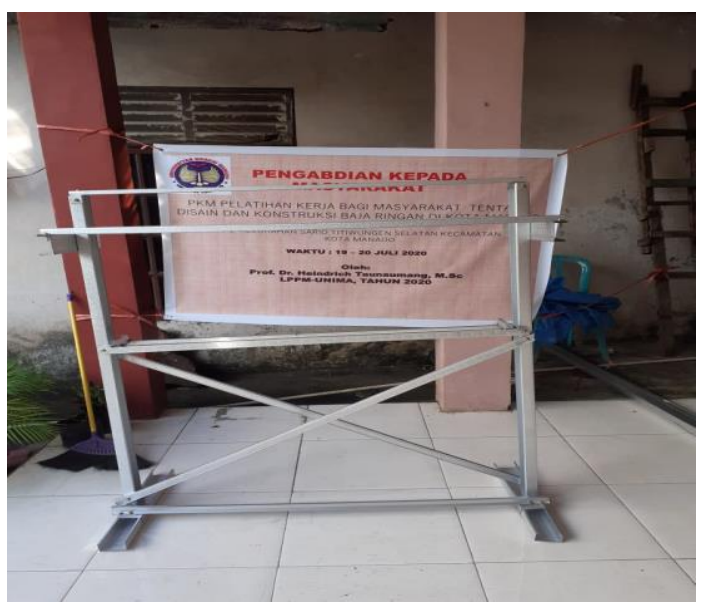


Jurnal ABDIMAS, Vol. 13, No. 1, April 2020

ISSN: 1979-0953 | e-ISSN: 2598-6066

Gambar 3.15. Konstruksi sederahana

gantungan handuk berbasis baja ringan .

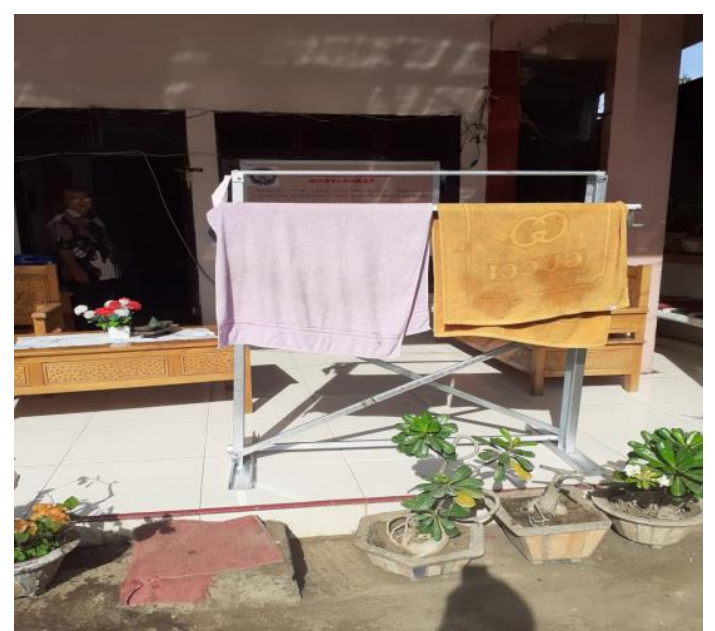

Gambar 3.16. Sudah dapat digunakan dengan layak.

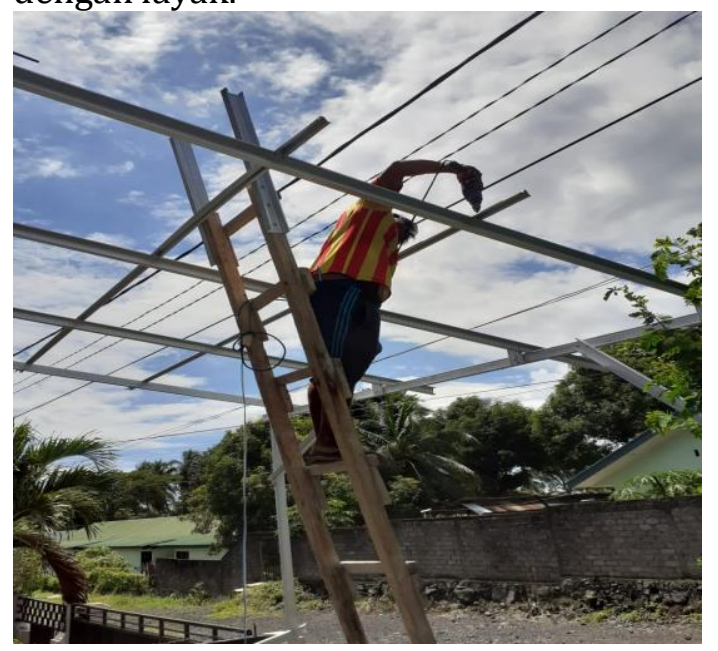

Gambar 3.17. Demonstrasi cara pembuatan garasi atap seng.

\subsection{Kesimpulan}

Melalui PPM Latihan Kerja ini para tukang /masyarakat di Kelurahan Titiwungen Selatan Kecamatan Sario Kota Manado telah berhasil meningkatkan pengetahuan dan ketrampilan untuk membuat disain dan konstruksi atap seng berbasis baja ringan.

\subsection{Saran}

Para tukang/masyarakat di Kelurahan

Titiwungen Selatan Kecamatan Sario Kota

Manado menyarankan agar PPM Latihan

Kerja ini kiranya dapat di kembangkan untuk pola /disain konstruksi yang lebih variatif.

\section{DAFTAR PUSTAKA}

https://www.google.com/search?client=firef ox-b-

d\&q=konstruksi+gantungan+baju+berbasis+ baja+ringan

https://indoberkainvestama.com/main/blog /detail/9/desain-baja-ringan-untuk-rumahyang-aman-dan-ramah-lingkungan 